\title{
Determination of excited singlet-state dipole moments of hydroxy and methoxy coumarins using solvatochromic method
}

\author{
Mohd Mudassir Husaina,*, Rajeev Sindhua,b and Harmesh Chander Tandonc \\ a Physics Section, Department of Applied Sciences and Humanities, Faculty of Engineering and Technology, Jamia Millia Islamia, a Central University, New Delhi- \\ 110025, India \\ b New Green Field College of Engineering and Technology, Palwal, Haryana-121102, India \\ c Department of Chemistry, Sri Venketswara College, Delhi University, New Delhi-110021, India \\ *Corresponding author at: Physics Section, Department of Applied Sciences and Humanities, Faculty of Engineering and Technology, Jamia Millia Islamia, a Central \\ University, New Delhi-110025, India. Tel.: +91.11.6831717x2512/2516; fax: +91.11.26988816. E-mail address: mmudassirh@rediffmail.com (M.M. Husain).
}

\section{ARTICLE INFORMATION}

Received: 02 August 2011

Received in revised form: 08 August 2011

Accepted: 12 August 2011

Online: 31 March 2012

\section{KEYWORDS}

\section{Coumarins}

Absorption

Stokes' shift

Fluorescence

Dipole moment

Solvatochromic

\section{Introduction}

Coumarin and their derivatives show remarkable biological, chemical and physical properties and are useful probes in photochemical studies [1-4]. Being highly fluorescent, coumarins act as fluorescent indicator, sunburn preventive and may be used in estimation of enzymes and has application in medicine [5-10]. The knowledge of absorption and fluorescence characteristics of these coumarins in various solvents and at different temperatures helps in understanding their use as laser dyes [11-14]. In the substituted coumarins; electron donating and withdrawing groups attached at various positions, alter their chemical reactivity in solvents of polar or non-polar nature. They also alter the dipole moment in ground and excited states. This helps in understanding the behavior of these compounds in ground and excited states [15-17].

The present work deals with the absorption and fluorescence characteristics of hydroxy and methoxy derivatives of 4-trifluoromethyl coumarins in different solvents of polar and non-polar nature. The absorption and fluorescence spectra of 7-hydroxy, 6,7-dihydroxy and 7-methoxy derivatives of 4-trifluoromethyl coumarin in various solvents are obtained and then the dipole moments in ground and excited states are calculated, using solvatochromic data. The excited state dipole moment of a dye is an important parameter, as it provides information about the change in electronic charge distribution due to excitation. A prior knowledge of the dipole moments in excited states is often useful in the design of non-linear optical material [18]. The solvatochromic technique gives important information about electronic transitions. Solvatochromic technique is quite useful for assignment of $n \rightarrow \pi^{*}$ or $\pi \rightarrow \pi^{*}$ transitions. It is a popular way to determine the dipole moments in ground and excited states for short-lived states [19-22]. This technique is based on a linear correlation between the wave numbers of the UV-VIS spectra of solute and solvent polarity function of $\varepsilon$ (dielectric constant) and $n$ (refractive index) of the solvent [23-36].

\section{Experimental}

\subsection{Chemicals}

The laser dyes 7-hydroxy-4-trifluoromethyl coumarin (7H4TFMC), 6,7-dihydroxy-4-trifluoromethyl coumarin (67DH4TFMC) and 7-methoxy-4-trifluoromethyl coumarin (7M4TFMC) in pure form were obtained from Sigma Aldrich Chemicals (USA) and used as received. The molecular structures of these dyes are given in Scheme 1. Where $\mathrm{R}_{1}=\mathrm{H}$, $\mathrm{R}_{2}=\mathrm{OH}$ for 7H4TFMC; $\mathrm{R}_{1}=\mathrm{OH}, \mathrm{R}_{2}=\mathrm{OH}$ for 67DH4TFMC and $\mathrm{R}_{1}=\mathrm{H}, \mathrm{R}_{2}=\mathrm{OCH}_{3}$ for 7M4TFMC. All the solvents used were of spectroscopic grade and were chosen in such a way that they were transparent and non-fluorescent in the range of excitation and fluorescence emission.

\subsection{Spectroscopic measurements}

The absorption and fluorescence spectra were recorded using Shimadzu- UV2450 and RF-5301PC spectrophotometer and spectrofluorometer, respectively. All the measurements were carried out at room temperature keeping dye concentration very low $\left(\sim 10^{-6} \mathrm{M}\right)$ in order to avoid self absorption. 
<smiles>[R2]c1cc2oc(=O)cc(C(F)(F)F)c2cc1[R2]</smiles>

7H4TFMC: $\mathrm{R}_{1}=\mathrm{H}, \mathrm{R}_{2}=\mathrm{OH}$ 67DH4TFMC: $\mathrm{R}_{1}=\mathrm{OH}, \mathrm{R}_{2}=\mathrm{OH}$ 7M4TFMC: $\mathrm{R}_{1}=\mathrm{H}, \mathrm{R}_{2}=\mathrm{OCH}_{3}$

Scheme 1

\subsection{Computational details}

The molecular orbital calculations have been carried out for these coumarins in gas phase. The ab-initio method with electron correlation function at Moller-Plesset 2 (MP2) level by using 6-31G standard basis set was used for this purpose. From the optimized geometry, the electronic and energetic parameters like dipole moment, in ground and excited state, frontier orbital energies, distribution of charge density and binding energies have been calculated. Throughout the computation, the r.m.s gradient and convergence limit were kept at $0.01 \mathrm{kcal} / \mathrm{mol} . \AA$ and 0.01 , respectively. For optimization process, HyperChem 7.52 package [37] is employed.

\section{Theoretical considerations}

The expression normally used in fluorescence spectroscopy is a simplified form of the equation first obtained by Lippert and Mataga et al. [38-41]. It is based on the Onsager's reaction field theory, which assumes that the fluorophore is a point dipole residing in the center of a spherical cavity with radius $a$ in a homogeneous and isotropic dielectric with relative permittivity $\varepsilon$. The Lippert-Mataga equation breaks down when in addition to the non-specific interactions, specific fluorophore-solvent interactions e.g., hydrogen bonding, electron-pair donor/electron-pair acceptor interactions also contribute significantly to the solute-solvent interaction. Another limitation results from the cavity radius, which is difficult to estimate for non-spherical molecule [20]. Here we report different solvent parameters, dielectric constant $(\varepsilon)$, refractive index $(n)$ and spectral parameters such as Stokes' shift which is useful for determination of dipole moments suggested by Bakshiev [42] and Kawski-Chamma-Viallet's [43]. They obtained a simplified quantum mechanical second order perturbation theory of absorption $\left(v_{a}\right)$ and fluorescence $\left(v_{f}\right)$ band shift in different solvents of varying permittivity $(\varepsilon)$ and refractive index $(n)$ relative to the band position of a solute molecule and based on which the following Equations are obtained.

$v_{a}-v_{f}=m_{1} F_{1}(\varepsilon, n)+$ const

$\frac{1}{2}\left(v_{a}+v_{f}\right)=-m_{2} F_{2}(\varepsilon, n)+$ const.

where $v_{a}$ and $v_{f}$ are the absorption and fluorescence maxima wave numbers in $\mathrm{cm}^{-1}$, respectively, $n$ and $\varepsilon$ are the refractive index and dielectric constant of the solvents, respectively.

The expression for $F_{1}(\varepsilon, n)$ [Bakshiev's polarity function] and $F_{2}(\varepsilon, n)$ [Kawski-Chamma-Viallet polarity function] are given as

$F_{1}(\varepsilon, n)=\frac{2 n^{2}+1}{n^{2}+2}\left[\frac{\varepsilon-1}{\varepsilon+2}-\frac{n^{2}-1}{n^{2}+2}\right]$

$$
F_{2}(\varepsilon, n)=\frac{1}{2} F_{1}+\frac{3}{2} \frac{\left(n^{4}-1\right)}{\left(n^{2}+2\right)^{2}}
$$

with

$$
\begin{aligned}
& m_{1}=\frac{2\left(\mu_{e}-\mu_{g}\right)^{2}}{h c a^{3}} \\
& m_{2}=\frac{2\left(\mu_{\mathrm{e}}^{2}-\mu_{\mathrm{g}}^{2}\right)}{h c a^{3}}
\end{aligned}
$$

Where $\mu_{\mathrm{e}}$ and $\mu_{\mathrm{g}}$ are excited state and ground state dipole moments of solute molecule respectively, ' $a$ ' is Onsager cavity radius , ' $h$ ' is Planck's constant and ' $c$ ' is the velocity of light in vacuum. The parameters $m_{1}$ and $m_{2}$ can be determined from absorption and fluorescence band shifts. If the ground and excited states are parallel then using above equations, the values of $\mu_{\mathrm{g}}$ and $\mu_{\mathrm{e}}$ can be obtained on the basis of Equations 5 and 6.

$\mu_{\mathrm{g}}=\frac{m_{2}-m_{1}}{2} \sqrt{\frac{h c a^{3}}{2 m_{1}}}$

$\mu_{\mathrm{e}}=\frac{m_{1}+m_{2}}{2} \sqrt{\frac{h c a^{3}}{2 m_{1}}}$

or

$\mu_{e}=\left[\frac{m_{1}+m_{2}}{m_{2}-m_{1}}\right] \mu_{g} \quad ; \quad m_{2}>m_{1}$

Hence the ratio of dipole moments in excited state and ground state is given by

$\frac{\mu_{e}}{\mu_{g}}=\frac{m_{1}+m_{2}}{m_{2}-m_{1}}$

The parameters $m_{1}$ and $m_{2}$ occurring for the differences $\left(v_{a^{-}}\right.$ $\left.v_{f}\right)$ and the sum $1 / 2\left(v_{a}+v_{f}\right)$ of the wave-numbers, are linear functions of the solvent polarity parameters $F_{1}(\varepsilon, n)$ and $F_{2}(\varepsilon$, $n$ ), respectively and can be determined from the slopes of the linear fits. The validity of the Equations 7 and 8 is based on certain assumption like considering both the dipole moments collinear or almost so. Also the same Onsager cavity radius ' $a$ ' in both ground and excited states is assumed.

The Onsager cavity radii ' $a$ ' from the molecular volume of molecules, given by Suppan's equation [44, 45].

$a=\sqrt[3]{\frac{3 \mathrm{M}}{4 \pi \rho \mathrm{N}}}$

where $M$ is the molecular weight of the dye; $\rho$ is the density of the dye, assumed as $1.0 \mathrm{~g} / \mathrm{cm}^{3}$ [46]; $\mathrm{N}$ being Avogadro's number, have been used to calculate the radii for the three coumarin derivatives in the present work. The value of ' $a$ ' has also been calculated at ab-initio level with 6-31G basis set for comparison. 
Table 1. Photo-physical parameters of 7H4TFMC in different solvents used ( $\lambda_{a}$ and $\lambda_{f}$ are wavelengths of absorption and fluorescence maxima, respectively).

\begin{tabular}{|c|c|c|c|c|c|c|}
\hline Solvent & $\lambda_{a}(\mathrm{~nm})$ & $\lambda_{f}(\mathrm{~nm})$ & $v_{a}\left(\mathrm{~cm}^{-1}\right)$ & $v_{f}\left(\mathrm{~cm}^{-1}\right)$ & $\left(v_{a}-v_{f}\right)\left(\mathrm{cm}^{-1}\right)$ & $1 / 2\left(v_{a}+v_{f}\right)\left(\mathrm{cm}^{-1}\right)$ \\
\hline Chloroform & 335.3 & 414.0 & 28384 & 21344 & 7040 & 24864 \\
\hline$n$-Butyl Acetate & 331.9 & 412.5 & 28003 & 21404 & 6599 & 24703 \\
\hline Ethyl Benzoate & 335.6 & 410.0 & 27708 & 21344 & 6364 & 24526 \\
\hline $\mathrm{CH}_{2} \mathrm{Cl}_{2}$ & 328.3 & 410.0 & 27862 & 21868 & 5994 & 24865 \\
\hline Ethyl Acetate & 330.9 & 410.0 & 28121 & 21177 & 6944 & 24649 \\
\hline Methanol & 336.4 & 433.6 & 27233 & 20064 & 7169 & 23648 \\
\hline DMSO & 338.8 & 434.2 & 26939 & 19446 & 7163 & 23202 \\
\hline Formamide & 339.2 & 441.0 & 26766 & 19603 & 7163 & 23184 \\
\hline
\end{tabular}

Table 2. Photo-physical parameters of 67DH4TFMC in different solvents used ( $\lambda_{a}$ and $\lambda_{f}$ are wavelengths of absorption and fluorescence maxima, respectively).

\begin{tabular}{|c|c|c|c|c|c|c|}
\hline Solvent & $\lambda_{a}(\mathrm{~nm})$ & $\lambda_{f}(\mathrm{~nm})$ & $v_{a}\left(\mathrm{~cm}^{-1}\right)$ & $v_{f}\left(\mathrm{~cm}^{-1}\right)$ & $\left(v_{a}-v_{f}\right)\left(\mathrm{cm}^{-1}\right)$ & $1 / 2\left(v_{a}+v_{f}\right)\left(\mathrm{cm}^{-1}\right)$ \\
\hline Toluene & 353.2 & 450.5 & 28312 & 22197 & 6115 & 25254 \\
\hline$n$-Butyl Acetate & 357.1 & 467.2 & 28003 & 21404 & 6599 & 24703 \\
\hline Ethyl Propionate & 358.3 & 470.3 & 27909 & 21263 & 6646 & 24586 \\
\hline Ethyl Benzoate & 360.9 & 468.5 & 27708 & 21344 & 6364 & 24526 \\
\hline Ethyl Acetate & 355.6 & 472.2 & 28121 & 21177 & 6944 & 24649 \\
\hline Acetone & 358.3 & 477.6 & 27909 & 20938 & 6971 & 24423 \\
\hline Methanol & 367.2 & 498.4 & 27233 & 20064 & 7169 & 23648 \\
\hline Acetonitrile & 354.5 & 477.1 & 28208 & 20959 & 7249 & 24583 \\
\hline DMF & 372.4 & 511.9 & 26852 & 19535 & 7317 & 23193 \\
\hline DMSO & 371.2 & 513.7 & 26939 & 19466 & 7473 & 23202 \\
\hline Formamide & 373.6 & 510.1 & 26766 & 19603 & 7163 & 23184 \\
\hline
\end{tabular}

Table 3. Photo-physical parameters of 7M4TFMC in different solvents used ( $\lambda_{a}$ and $\lambda_{f}$ are wavelengths of absorption and fluorescence maxima, respectively).

\begin{tabular}{|c|c|c|c|c|c|c|}
\hline Solvent & $\lambda_{a}(\mathrm{~nm})$ & $\lambda_{f}(\mathrm{~nm})$ & $v_{a}\left(\mathrm{~cm}^{-1}\right)$ & $v_{f}\left(\mathrm{~cm}^{-1}\right)$ & $\left(v_{a}-v_{f}\right)\left(\mathrm{cm}^{-1}\right)$ & $1 / 2\left(v_{a}+v_{f}\right)\left(\mathrm{cm}^{-1}\right)$ \\
\hline$n$-Hexane & 326.0 & 400.0 & 30590 & 25000 & 5590 & 27795 \\
\hline Cyclohexane & 328.7 & 402.5 & 30422 & 24844 & 5578 & 27633 \\
\hline Toluene & 333.7 & 411.1 & 29967 & 24324 & 5643 & 27145 \\
\hline Ethyl Benzoate & 334.9 & 415.0 & 29859 & 24096 & 5763 & 26977 \\
\hline Decanol & 333.7 & 412.9 & 29967 & 24218 & 5749 & 27092 \\
\hline $\mathrm{CH}_{2} \mathrm{Cl}_{2}$ & 334.9 & 411.6 & 29994 & 24295 & 5699 & 27144 \\
\hline Octanol & 333.7 & 412.0 & 30048 & 24271 & 5777 & 27159 \\
\hline Heptanol & 333.4 & 416.1 & 29913 & 24032 & 5881 & 26972 \\
\hline Hexanol & 334.1 & 413.4 & 29931 & 24166 & 5765 & 27048 \\
\hline Butanol & 333.4 & 414.3 & 29994 & 24137 & 5857 & 27065 \\
\hline Ethanol & 332.7 & 414.3 & 30057 & 24137 & 5920 & 27097 \\
\hline Formamide & 336.4 & 420.6 & 29726 & 23775 & 5951 & 26750 \\
\hline
\end{tabular}

Table 4. Values of solvent parameters $(\varepsilon, n)$ and solvent polarity parameters $F_{1}(\varepsilon, n)$ and $F_{2}(\varepsilon, n)$ of different solvents $(\varepsilon$ and $n$ are from Ref. [20,46]).

\begin{tabular}{|c|c|c|c|c|}
\hline Solvent & $\varepsilon$ & $n$ & $F_{1}(\varepsilon, n)$ & $F_{2}(\varepsilon, n)$ \\
\hline$n$-Hexane & 1.88 & 1.374 & -0.0015 & 0.253 \\
\hline Cyclohexane & 2.02 & 1.426 & -0.003 & 0.287 \\
\hline Toluene & 2.38 & 1.497 & 0.028 & 0.349 \\
\hline Chloroform & 4.81 & 1.442 & 0.370 & 0.490 \\
\hline$n$-Butyl Acetate & 5.00 & 1.394 & 0.413 & 0.471 \\
\hline Ethyl Propionate & 5.58 & 1.380 & 0.460 & 0.489 \\
\hline Ethyl Benzoate & 5.99 & 1.503 & 0.430 & 0.550 \\
\hline Ethyl Acetate & 6.08 & 1.372 & 0.492 & 0.499 \\
\hline Decanol & 8.00 & 1.437 & 0.553 & 0.571 \\
\hline $\mathrm{CH}_{2} \mathrm{Cl}_{2}$ & 8.93 & 1.424 & 0.595 & 0.584 \\
\hline Octanol & 9.80 & 1.429 & 0.614 & 0.604 \\
\hline Heptanol & 11.30 & 1.424 & 0.652 & 0.618 \\
\hline Hexanol & 13.30 & 1.418 & 0.686 & 0.627 \\
\hline Butanol & 17.40 & 1.399 & 0.749 & 0.648 \\
\hline Acetone & 21.01 & 1.359 & 0.792 & 0.640 \\
\hline Ethanol & 24.30 & 1.361 & 0.810 & 0.650 \\
\hline Methanol & 33.70 & 1.329 & 0.857 & 0.652 \\
\hline Acetonitrile & 36.64 & 1.344 & 0.861 & 0.665 \\
\hline DMF & 37.00 & 1.426 & 0.850 & 0.650 \\
\hline DMSO & 47.24 & 1.497 & 0.841 & 0.744 \\
\hline Formamide & 111.0 & 1.447 & 0.895 & 0.750 \\
\hline
\end{tabular}

\section{Results and discussion}

Absorption and emission spectra of the three coumarin dyes were measured in solvents of different dielectric constant $(\varepsilon)$ and refractive index $(n)$ values. The emission spectra were measured by exciting the sample at its longest absorption maximum. The observed absorption and emission maxima, wave numbers, Stokes' shift $\left(v_{a}-v_{f}\right)$ and $1 / 2\left(v_{a}+v_{f}\right)$ of the three molecules are listed in Tables 1-3. It can be seen that the charge transfer band shows a shift of about $20 \mathrm{~nm}$ in the absorption spectra on changing the solvent whereas emission spectra show larger shift as compared to the absorption. The smaller variation in the absorption shift with solvent indicates that the ground state energy distribution is not affected to a greater extent possibly due to the less polar nature of the dyes in ground state rather than the excited state. The values of solvent parameters $(\varepsilon, n)$ along with the polarity functions $F_{1}(\varepsilon, n)$ and $F_{2}(\varepsilon, n)$ are tabulated in Table 4. It can be seen that the Stokes' shift is also large. The large Stokes' shift is also indicative of the charge transfer transition. The large magnitude of the Stokes' shift indicates that the excited state geometry could be different from that of the ground state. The general observation is that there is an increase in the Stokes' shift values with increasing solvent polarity indicating that there is an increase in the dipole moment on excitation. In such cases, the relaxed excited singlet-state $S_{1}$ will be energetically stabilized relative to the ground state $S_{0}$ and a significant red shift of fluorescence is observed.

Figures 1 and 2 show graphs of the spectral shifts $\left(v_{a}-v_{f}\right)$ and $1 / 2\left(v_{a}+v_{f}\right)$ (in $\left.\mathrm{cm}^{-1}\right)$ of 7H4TFMC with polarity functions $F_{1}(\varepsilon, n)$ and $F_{2}(\varepsilon, n)$. 
Table 5. Dipole moments (calculated experimentally), slopes ( $m_{1}$ and $\left.m_{2}\right)$, Onsager radius and correlation coefficients of coumarin dyes*

\begin{tabular}{|c|c|c|c|c|c|c|c|c|}
\hline Solute molecule & $m_{1}\left(\mathrm{~cm}^{-1}\right)$ & $m_{2}\left(\mathrm{~cm}^{-1}\right)$ & Radius $a(\AA)$ & $\mu_{\mathrm{g}}(\mathrm{D})$ & $\mu_{\mathrm{e}}$ (D) & $\Delta \mu=\mu_{\mathrm{e}}-\mu_{\mathrm{g}}(\mathrm{D})$ & $\mu_{\mathrm{e}} / \mu_{\mathrm{g}}$ & Correlation Coefficients \\
\hline \multirow[t]{2}{*}{ 7H4TFMC } & 1959.90 & 3812.31 & 4.50 (Equation 1$)$ & 1.99 & 6.20 & 4.21 & 3.11 & 0.95 \\
\hline & & & 3.26 (Ab-initio) & 1.77 & 5.56 & 3.79 & 3.14 & 0.85 \\
\hline \multirow[t]{2}{*}{ 67DH4TFMC } & 1411.92 & 4707.94 & 4.60 (Equation 1$)$ & 4.31 & 8.01 & 3.70 & 1.85 & 0.92 \\
\hline & & & 3.28 (Ab-initio) & 3.52 & 6.56 & 3.04 & 1.86 & 0.88 \\
\hline \multirow[t]{2}{*}{ 7M4TFMC } & 351.35 & 1610.72 & 4.59 (Equation 1) & 3.23 & 5.07 & 1.84 & 1.56 & 0.91 \\
\hline & & & 3.79 (Ab-initio) & 2.36 & 3.67 & 1.31 & 1.55 & 0.86 \\
\hline
\end{tabular}

${ }^{*} m_{1}$ and $m_{2}$ are the slopes of $\left(v_{a^{-}} v_{f}\right)$ vs. $F_{1}(\varepsilon, n)$ and $1 / 2\left(v_{a}+v_{f}\right)$ vs. $F_{2}(\varepsilon, n)$, respectively; ' $a$ ' is the Onsager radius; $\mu_{\mathrm{e}}$ and $\mu_{\mathrm{g}}$ are the dipole moments in ground and excited state, respectively.

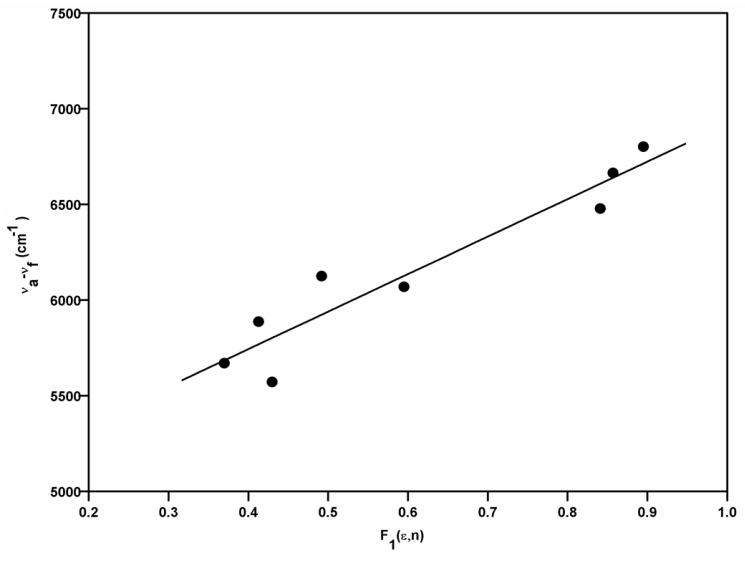

Figure 1. Linear fit of $\left(v_{a}-v_{f}\right)$ vs. $F_{1}(\varepsilon, n)$ of 7H4TFMC in solvents listed in Table 1.

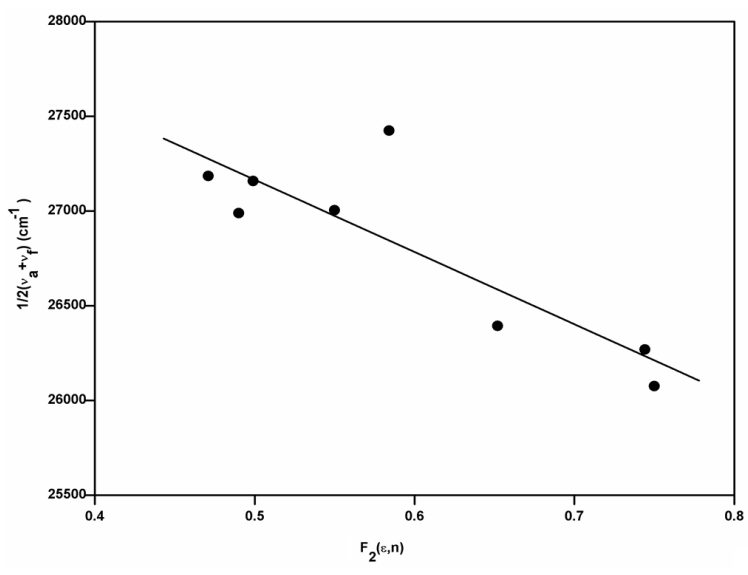

Figure 2. Linear fit of $1 / 2\left(v_{a}+v_{f}\right)$ vs. $F_{2}(\varepsilon, n)$ of 7H4TFMC in solvents listed in Table 1.

Figure $3 \mathrm{a}$ and $3 \mathrm{~b}$ shows the electronic absorption (UV-vis) and fluorescence emission spectra of 7H4TFMC in various solvents with different polarity. The slopes $\left(m_{1}\right.$ and $\left.m_{2}\right)$ of the least square fit were taken to calculate the ground and excited state dipole moment of the three dyes. The slopes ( $m_{1}$ and $\left.m_{2}\right)$ are displayed in Table 5. The values of $m_{1}$ and $m_{2}$ are then used in the Equations 7 and 8 to calculate the dipole moments $\left(\mu_{\mathrm{g}}\right.$ and $\mu_{\mathrm{e}}$ ) of all the three dyes. The dipole moments $\mu_{\mathrm{g}}$ and $\mu_{\mathrm{e}}$ depend not only on $m_{1}$ and $m_{2}$ but also on radius of the solute. The values of change in dipole moment $\left(\Delta \mu=\mu_{\mathrm{e}}-\mu_{\mathrm{g}}\right)$ obtained are $4.21 \mathrm{D} ; 3.70 \mathrm{D}$ and $1.84 \mathrm{D}$ when the radius of the systems is calculated by Equations 11 and $3.79 \mathrm{D} ; 3.04 \mathrm{D}$ and $1.31 \mathrm{D}$ when radius is calculated by ab-initio method for 7H4TFMC, 67DH4TFMC, and 7M4TFMC, respectively. The linear dependence of spectral shifts on polarity functions shows a good correlation (see Table 5). The first correlation coefficient corresponds to the graph between $\left(v_{a}-v_{f}\right)$ and $F_{1}(\varepsilon, n)$ and second corresponds to the graph between $1 / 2\left(v_{a}+v_{f}\right)$ and $F_{2}(\varepsilon, n)$, respectively. It is clear that on increasing solvent polarity, both absorption and emission bands undergo bathchromic shift (red shift). This means that there is charge transfer (CT) absorption of the less dipolar ground-state molecule with dominant mesomeric structure, leading to highly dipolar excited state and with the prominent structure of coumarins. A bathchromic shift upon increasing the solvent polarity of the solvent indicates as $\pi \rightarrow \pi^{*}$ transition. Further, substituents have a marked effect on the position of absorption $\left(v_{a}\right)$ and fluorescence maxima $\left(v_{f}\right)$.

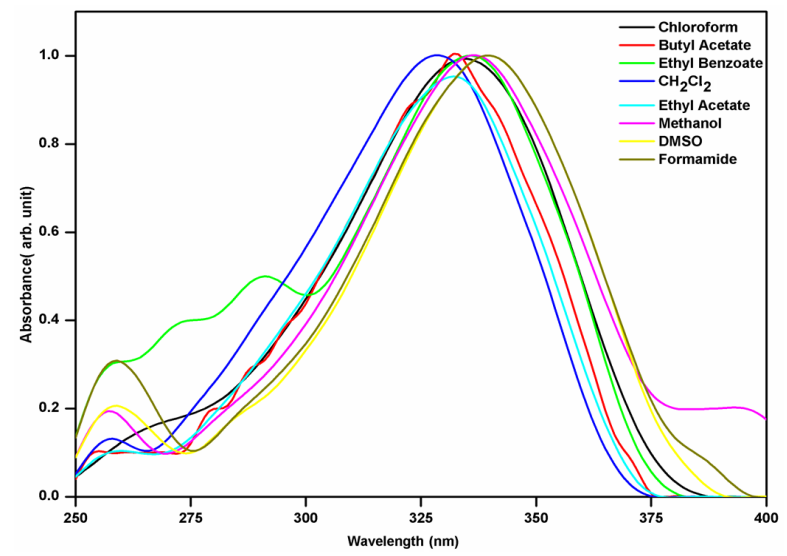

(a)

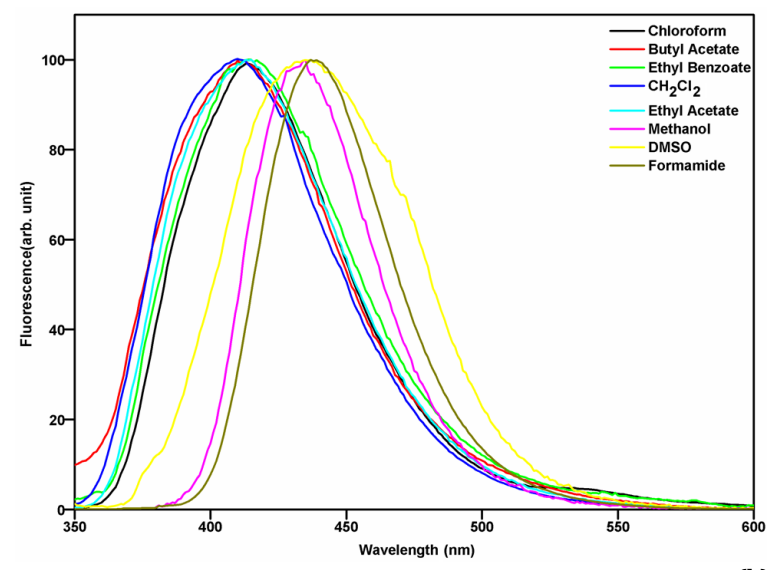

(b)

Figure 3. Absorption (a) and fluorescence (b) spectra of 7H4TFMC in different solvents.

The molecular orbital calculations have also been carried out for these coumarin derivatives and the results are displayed in Tables 6-7. Recently, D. Mitnik [48] carried out computational calculation of coumarin derivatives to show the usefulness of these molecules for photovoltaic application on the basis of HOMO-LUMO orbitals The highest occupied molecular orbital, HOMO, and the lowest unoccupied molecular orbital, LUMO, of a molecule are called the frontier orbitals.

It was Fukui [49] who first noticed the prominent role played by HOMO and LUMO in governing chemical reactions. 
Table 6. Energetic and electronic parameters of the coumarins at MP2/6-31G level*.

\begin{tabular}{|c|c|c|c|c|c|c|}
\hline System & $\begin{array}{l}\text { Binding Energy } \\
\text { (E) (kcal/mol) }\end{array}$ & $\begin{array}{l}\text { Dipole moment } \\
\mu \text { (D) }\end{array}$ & $\Delta \mu=\mu_{\mathrm{e}}-\mu_{\mathrm{g}}[\mathrm{D}]$ & HOMO (ev) & LUMO (ev) & $\Delta E$ \\
\hline 7H4TFMC & -567382.7 & $\begin{array}{l}9.181 \\
(9.375)\end{array}$ & 0.194 & $\begin{array}{l}-9.8679 \\
(-9.8834)\end{array}$ & $\begin{array}{l}0.2224 \\
(0.2037)\end{array}$ & 10.0904 \\
\hline 67DH4TFMC & -614337.8 & $\begin{array}{l}9.165 \\
(9.827)\end{array}$ & 0.662 & $\begin{array}{l}-9.0252 \\
(-8.8415)\end{array}$ & $\begin{array}{l}0.3803 \\
(0.0087)\end{array}$ & 8.8867 \\
\hline 7M4TFMC & -591856.6 & $\begin{array}{l}9.976 \\
(10.68)\end{array}$ & 0.704 & $\begin{array}{l}-9.7347 \\
(-9.5552)\end{array}$ & $\begin{array}{l}0.4487 \\
(0.3937)\end{array}$ & 11.2390 \\
\hline
\end{tabular}

*The numbers in the parentheses are the values in singly excited states.

Table 7. Net atomic charge on oxygen atom.

\begin{tabular}{|c|c|c|c|c|c|}
\hline \multirow[t]{2}{*}{ System } & \multirow[t]{2}{*}{ Ring 0-atom } & \multicolumn{4}{|c|}{ Atoms } \\
\hline & & $\mathrm{O}(\mathrm{C}=0)$ & 6-0 (OH) & 7-0 (OH) & $7-0\left(\mathrm{OCH}_{3}\right)$ \\
\hline$\overline{\text { 7H4TFMC }}$ & -0.801 & -0.610 & - & -0.793 & - \\
\hline 67DH4TFMC & -0.765 & -0.615 & -0.760 & -0.757 & - \\
\hline 7M4TFMC & -0.804 & -0.610 & - & - & -0.780 \\
\hline
\end{tabular}

It has been revealed by recent investigation that the gap in energy between the HOMO and LUMO is an important stability index [50-52]. A large gap implies high stability and small gap implies low stability. The high stability in turn indicates low chemical reactivity and small a gap indicates high chemical reactivity. It can be seen from the results that the energy gap $(\Delta E)$ between HOMO and LUMO state which are termed as chemical descriptor, is least in 67DH4TFMC suggestive of its high chemical reactivity and basic nature in comparison to other two dyes (Table 6). Because of this behavior, this molecule shows maxima in absorption spectra, in highly polar solvent. This observation correlates well with the solvent formamide in which it gives maximum $\lambda_{a}$ (Tables 1-3). The net atomic charge on 0-atom in these molecules is listed in Table 7. The carbonyl group in 67DH4TFMC is most reactive and capable of forming H-bond complex with aprotic solvents. Earlier, the molecular orbital treatment was studied for the electronic absorption spectra of coumarins by Rafie and Bahget [53]. They used semi-empirical method INDO for this purpose and concluded that $\pi \rightarrow \pi^{*}$ transition band is more dominant than $n \rightarrow \pi^{*}$ band. Later, N. Agmon [54] studied the proton transfer reaction in excited state for some $\alpha$ and $\beta$-Napthols.

\section{Conclusion}

The effect of protic, aprotic and non-polar solvents, on the absorption spectra and fluorescence emission spectra of the coumarin derivatives show that the dipole moments in the singly excited singlet-state are larger than the ground state. They all show $\pi \rightarrow \pi^{*}$ transition than $n \rightarrow \pi^{*}$ transition. These observations indicate the electrostatic and H-bond interactions. The computed values of the energy gap $(\Delta E)$ of these molecules suggest that 67DH4TFMC is found to be most reactive chemically and can be useful as laser dye.

\section{Acknowledgements}

This work is supported by The University Grants Commission through a research grant provided to one of the authors (Mohd Mudassir Husain) and Department of Applied Sciences and Humanities, Faculty of Engineering and Technology, Jamia Millia Islamia, New Delhi, India.

\section{References}

[1]. Fletcher, A. N.; Bliss, D. E. Appl. Phys. 1978, 16, 289-295

[2]. Halstead, J. A.; Reeves, R. R. Opt Commun. 1978, 27, 273-276

[3]. Gardecki, J. A.; Maroncelli, M. J. Phys. Chem. 1999, 103, 1187-1197.

[4]. Levinger, N. E. Curr. Opin. Colloid Interf. Sci. 2000, 5, 118-124.

[5]. Castner, J. E. W.; Kennedy, D.; Cave, R. J. J. Phys. Chem. A 2000, 104, 2869-2885.

[6]. Morandeira, A.; Fulrstenberg, A.; Vauthey, E. J. Phys. Chem. A 2004, $108,8190-8200$

[7]. Kumbhakar, M.; Nath, S.; Mukherjee, T.; Pal, H. J. Chem. Phys 2004, $121,6026-6033$
[8]. Wattenburg L. W. Lam, L. K. Fladmore, A. V. Cancer Res. 1999, 39, 1651-1654

[9]. Cassady, J. M.; Ojima, N.; Chang, C. J.; Mcloughlin, J. L. J. Nat. Prod. 1979, 42, 274-278.

[10]. Finnegan, R. A.; Merkel, K. E.; Back, N. J. Pharm. Sci. 1972, 61, 15991603.

[11]. Giri, R.; Rathi, S. S.; Machwe, M. K. Spectrochim. Acta A 1992, 48, 843-

[12]. Moriya, T. Bull. Chem. Soc. Jpn. 1984, 57, 1723-1730

[13]. EI-Ansary, A. L.; Ebeid, E. M.; Omar, M. M. Spectrochim. Acta A 1987 43, 709-710.

[14]. Schulman, S. G. (Ed.), Molecular Luminescence Spectroscopy, Methods and Applications, Wiley, New York, 1985.

[15]. Kumar, S.; Rao, V. C.; Rastogi, R. C. Spectrochim. Acta Part A 2001, 57 41-47.

[16]. Sharma, V. K.; Saharo, P. D.; Rastogi, R. C. Spectrochim. Acta A 2003 59, 1161-1170.

[17]. Murray, R. D. H. Natl. Prod. Rep. 1989, 6, 591-624.

[18]. Ravi, M.; Soujanya, T.; Samanta, A.; Radhakrishnan, T. P. J. Chem. Soc. Faraday Trans. 1995, 91, 2739-2742.

[19]. Mannekutla, J. R.; Mulimani, B. G.; Inamdar, S. R. Spectochim. Acta A 2008, 69, 419-426.

[20]. Aaron, J. J.; Buna, M.; Parkanyi, C.; Antonious, M. S.; Tine, A. J. Fluoresc. 1995, 5, 337-348.

[21]. Onager, L. J. Am. Chem. Soc. 1936, 58, 1482-1486.

[22]. Kirkwood, J. G. J. Chem. Phys. 1939, 7, 911-919.

[23]. Nadaf, Y. D.; Deshpande, D. K.; Karaguppikar, A. M.; Inamdar, S. R. J. Photosci. 2002, 9, 29-35.

[24]. Kawski, A. Z. Natureforsch. 2002, 57A, 255-262.

[25]. Evale, B. G.; Hanagodimath, S. M.; Khan, I. A.; Kulkarni, M. V. Spectochim. Acta A 2009, 73, 694-700.

[26]. Thipperudrappa, J.; Biradar, D. S.; Manohara, S. R.; Hangodimath, S. M. S. R. Inamdar, S. R Spectrochim. Acta A 2008, 69, 991-997.

[27]. Siddlingeshwar, B.; Hanagodimath, S. M. Spectrochim. Acta A 2009, 72 490-495.

[28]. Raikar, U. S.; Renuka, C. G.; Nadaf, Y. F.; Mulimani, B. G.; Karguppikar, A. M.; Soudagar, M. K. Spectrochim. Acta A 2006, 65, 673-677.

[29]. Kumar, S.; Jain, S. K.; Rastogi, R. C Spectrochim. Acta A 2001, 57, 291 298.

[30]. Cisse, L.; Djande, A.; Capo-Chichi, M.; Aaron, J. J. Spectrochim. Acta A 2011, 79, 428-436.

[31]. Zakerhamidi, M. S.; Ghanadzadeh, A.; Moghadam, M. Spectrochim. Acta A 2011, 78, 961-966.

[32]. Inamdar, S. R.; Nadaf, Y. F.; Mulimani, B. G. J. Mol. Struct. 2003, 624, 47-51.

[33]. Zakerhamidi, M. S.; Ghanadzadeh, A.; Moghadam, M.; Tajalli, H. Spectrochim. Acta A 2010, 77, 767-772.

[34]. Siddlingeshwar, B.; Hanagodimath, S. M.; Kirilova, E. M. J. Quant Spectrosc. Radiat. Trans. 2011, 112, 448-456.

[35]. Jozefowicz, M.; Milart, P.; Heldt, J. R. Spectrochim. Acta A 2009, 74, 959-963.

[36]. Sundstrom, V.; Gilbro, T. Chem. Phys. Lett. 1984, 109, 538-543.

[37]. HYPERCHEM 7. 52, Hypercube Inc., Florida, 2003.

[38]. Lippert, E. Z. Naturforch, Part A 1955, 10, 541-545.

[39]. Lippert, E. Elektrochem, Ber. Bunsenges. Phys. Chem. 1957, 61, 962 975.

[40]. Mataga, N.; Kaifu, Y.; Koizumi, M. Bull. Chem. Soc. Jpn. 1956, 29, 465 470.

[41]. Mataga, N.; Kubota, T. Molecular Interactions and Electronic Spectra, Dekker, New York, 1970

[42]. Bakshiev, N. G. Opt. Spektosk. (USSR) 1964, 16, 821-832.

[43]. Chamma, A.; Viallet, P. C. R. Acad. Sci. Paris, Ser. C 1970, 270, 19011904.

[44]. Suppan, P. Chem. Phys. Lett. 1983, 94, 272-275. 
[45]. Ghazy, R.; Azim, S. A, ; Shaheen, M. F. El-Mekawey Spectrochim. Acta A 2004, 60, 187-191.

[46]. Zachariasse, K. Private communication, $6^{\text {th }}$ International Conference on Solar Energy and Applied Photochemistry, "Solar'01", 3-8 April 2001, Cairo.

[47]. Lide, D. R. CRC Handbook of Chemistry and Physics, $79^{\text {th }}$ Edn. CRC.

48]. Mitnik, D. J. Mol. Struct. (Theochem) 2009, 911, 105-108.

[49]. Fukui, K.; Yonezawa, T.; Shingu, H. J. Chem. Phys. 1952, 20, 722-725.

[50]. Pearson, R. G. J. Org. Chem. 1989, 54, 1423-1430.

[51]. Zhou, Z.; Parr, R. G. J. Am. Chem. Soc. 1990, 112, 5720-5724.

[52]. Faust, W. L. Science 1989, 245, 37-42.

[53]. Rafie, H.; Bahget Ali, H. Can. J. Chem. 1985, 63, 1173-1179.

[54]. Agmon, N. J. Phys. Chem. A 2005, 109, 13-35. 